Article

\title{
Ameliorative Effect of Bacillus subtilis on Growth Performance and Intestinal Architecture in Broiler Infected with Salmonella
}

\author{
Alaeldein M. Abudabos ${ }^{1, *}$, Muttahar H. Ali ${ }^{1}$, Mohammed A. Nassan ${ }^{2}$ and Ahmad A. Saleh ${ }^{3}$ (D) \\ 1 Department of Animal Production, College of Food and Agriculture Sciences, King Saud University, \\ P.O. Box 2460, Riyadh 11451, Saudi Arabia; muttahar2013@gmail.com \\ 2 Department of Pathology, Faculty of Veterinary Medicine, Zagazig University, Zagazig 44511, Egypt; \\ moh_nassan@yahoo.com \\ 3 Department of Poultry Production, Faculty of Agriculture, Kafrelsheikh University, \\ Kafr El-Sheikh 333516, Egypt; a_saleh2006@yahoo.com \\ * Correspondence: aabudabos@ksu.edu.sa; Tel.: +966-57634578; Fax: +966-11-4678474
}

Received: 6 March 2019; Accepted: 12 April 2019; Published: 23 April 2019

Simple Summary: Salmonellosis is a dangerous disease in broilers that causes huge economic losses. We assumed that instead of antibiotics, a Bacillus-based probiotic may serve as an alternative to alleviate the negative effects of Salmonella infection. A control group with no feed additive, a positive control supplemented with a standard antibiotic and two groups that were supplemented with different strains and levels of Bacillus subtilis were the experimental animals of the present study. It was revealed that supplementation of probiotic bacteria induced similar results in terms of feed intake, body weight gain and feed efficiency in comparison with the group treated with antibiotics. In addition, the dimensions of intestinal villi were also improved in the probiotic-treated birds. As concluded from the results of the present study, probiotic bacteria could be used as an alternative to antibiotics against Salmonella in broilers.

\begin{abstract}
A total of 600 day-old broiler chicks (Ross 308) confirmed for the absence of Salmonella were randomly allocated to five treatments each with 10 replicates: negative control (basal diet only); positive control (basal diet) + infected with Salmonella; T1, Salmonella infected + avilamycin; T2, Salmonella infected + Bacillus subtilis (ATCC PTA-6737; $2 \times 10^{7} \mathrm{CFU} / \mathrm{g}$ ) and T3, Salmonella infected + B. subtilis (DSM 172999; $1.2 \times 10^{6} \mathrm{CFU} / \mathrm{g}$ ). The results revealed that feed intake (FI) and body weight (BW) were significantly $(p<0.01)$ lower in T1 compared to T2. The feed conversion ratio (FCR) was significantly $(p<0.01)$ lower in T2 and T3 compared to other treatments. Similarly, the performance efficiency factor (PEF) was also significantly $(p<0.01)$ higher in T2 and T3 compared to positive control. Villus height was significantly $(p<0.01)$ higher in T2 compared to all other treatments. However, villus width and surface area were significantly $(p<0.01)$ higher in T1. In conclusion, dietary supplementation with $B$. subtilis improved growth and intestinal health by reversing the negative effects of Salmonellosis.
\end{abstract}

Keywords: broiler; growth; intestinal villi; Salmonella

\section{Introduction}

In the modern broiler industry, antimicrobials used as growth promoters are among the most popular synthetic agents used in poultry production for the improvement of feed efficiency and the reduction of microbial pathogenesis [1,2]. Antimicrobials as an additive have produced promising results; however, their regular use has caused drug resistance and residues in eggs and meat [3]. 
Under such circumstances, many countries are considering a strict ban or have already banned (European Union) the use of Antimicrobial growth promoters (AGPs) [4-6]. Therefore, there is a necessity to find suitable alternatives that could replace AGPs. Recently natural products have gained special interest, since they improve growth performance and reduce mortality rates as an effect of infectious agents [7-9].

Salmonella is one of the most important poultry diseases causing heavy economic losses through stunted growth and increased mortality rates [6,8]. Incidences of Salmonella are most frequent during the starter phase, since the immune system of the chick is not well developed [9]. Chickens are frequently exposed to Salmonella during their life and micro-organisms can be readily transferred to humans through the consumption of poultry meat, causing severe gastrointestinal symptoms [10]. A number of practices are used to reverse the symptoms of salmonellosis in broilers including the use of probiotics $[9,11]$. Probiotics are used in poultry production due to the wide range of their positive effects [11]. Probiotics are now considered an alternative to antibiotics and added in the animals' diet as a microbial supplement [12]. It has been reported that probiotics enhance growth, provide protection against a wide range of pathogens and improve immunity [11-13]. Bacillus subtilis is naturally isolated from the gut of chickens and it is known to produce antimicrobial substances such as surfactants [11]. Recently, it was reported that $B$. subtilis improved the growth and antioxidant status in broilers exposed to Salmonella [8]. In the literature, positive effects of the two strains of B. subtilis have been reported; however, their comparative effects have not been described. The aim of the present study was to evaluate the effects of two different strains of $B$. subtilis on the performance and intestinal health of Salmonella-infected broilers during the starter phase.

\section{Methods}

\subsection{Animals and Feeding Practices and Randomization}

A total of 600 day-old broiler chicks (Ross 308) were randomly divided into five treatments (10 replicates and 12 birds per replicate). On arrival, all chicks were confirmed for the absence of Salmonella. The experiment was carried out in an environmentally controlled closed poultry unit. Straw was used as bedding material on the concrete floor. Initially the temperature was set to $31^{\circ} \mathrm{C}$ and gradually decreased to a thermoneutral temperature of $22-24^{\circ} \mathrm{C}$ and a relative humidity of $70 \%$. An automated exhaust fan drew outside air in at $45.8 \mathrm{~m}^{3} / \mathrm{min}$. The photoperiod was maintained at 23:1 L:D at the intensity rate of 20 lux using cool light fluorescent tubes. The stocking density was maintained at $50 \mathrm{~kg} / \mathrm{m}^{2}$.

Broiler chicks were raised according to the recommendations of the Ross guide. A standard starter (0-15) diet with isocaloric and isonitrogenous contents was offered in a mash form based on corn-SBM and was formulated to meet the requirements of the broilers (Table 1). On day 1, chicks received one of five treatments randomly as follows: negative control (basal diet); positive control (basal diet) + infected with Salmonella enterica, subspecies typhimurium; T1, infected with Salmonella + avilamycin $(0.2 \mathrm{~g} / \mathrm{kg})$; T2, infected + probiotics that have viable spores of B. subtilis (ATCC PTA-6737; $\left(2 \times 10^{7} \mathrm{CFU} / \mathrm{g}\right)$ and T3, infected + B. subtilis (DSM 17299; $\left.1.2 \times 10^{6} \mathrm{CFU} / \mathrm{g}\right)$.

Table 1. Dietary composition of broiler chicken starter diets.

\begin{tabular}{cc}
\hline Ingredient (\%) & Starter Phase \\
\hline Yellow corn & 57.39 \\
Soybean meal & 27.00 \\
Palm oil & 2.20 \\
Corn gluten meal & 8.80 \\
Dicalcium phosphate & 2.30 \\
Ground limestone & 0.70 \\
Choline chloride & 0.05 \\
DL-methionine & 0.10 \\
\hline
\end{tabular}


Table 1. Cont.

\begin{tabular}{cc}
\hline Ingredient (\%) & Starter Phase \\
\hline L-lysine & 0.39 \\
Salt & 0.40 \\
Threonine & 0.17 \\
V-M vitamins-minerals premix ${ }^{1}$ & 0.50 \\
\hline Analyses & \\
ME Metabolizable energy, kcal/kg & 3000 \\
Crude protein, \% & 23.0 \\
Non phytate P, \% & 0.48 \\
Calcium, \% & 0.96 \\
D. Lysine, \% & 1.28 \\
D. Methionine, \% & 0.60 \\
Sulfur amino acids, \% & 0.95 \\
Threonine, \% & 0.86
\end{tabular}

\footnotetext{
${ }^{1}$ Vitamin-mineral premix contains the following per kg: vitamin A, 2,400,000 IU; vitamin D, 1,000,000 IU; vitamin E, $16,000 \mathrm{IU}$; vitamin K, $800 \mathrm{mg}$; vitamin B1, $600 \mathrm{mg}$; vitamin $\mathrm{B}_{2}, 1600 \mathrm{mg}$; vitamin $\mathrm{B}_{6}, 1000 \mathrm{mg}$; vitamin $\mathrm{B}_{12}, 6 \mathrm{mg}$; niacin, $8000 \mathrm{mg}$; folic acid, $400 \mathrm{mg}$; pantothenic acid, $3000 \mathrm{mg}$; biotin $40 \mathrm{mg}$; antioxidant, $3000 \mathrm{mg}$; cobalt, $80 \mathrm{mg}$; copper, $2000 \mathrm{mg}$; iodine, 400; iron, $1200 \mathrm{mg}$; manganese, 18,000 mg; selenium, $60 \mathrm{mg}$; zinc, 14,000 mg.
}

\subsection{Challenge Inoculum}

On the second day, all groups apart from the negative control were orally administered with a $3 \times 10^{9}$ live culture of Salmonella enterica subspecies typhimurium as described by Abudabos et al. [9].

\subsection{Growth Performance}

Growth performance parameters such as body weight (BW), feed intake (FI) and feed conversion rate (FCR) were recorded at five-day intervals. The BW was measured on an electronic digital balance with a sensitivity of $0.1 \mathrm{~g}$ (Berkley, Columbia, SC, USA). The production efficiency factor (PEF) was calculated as described by Abudabos et al. [6].

\subsection{Sitophological Measurements}

Histological study of intestinal tissue was conducted as described by Rahman et al. [14]. On day 15, 10 birds per treatment were randomly selected. For histological studies, about $2 \times 2 \mathrm{~cm}^{2}$ long samples from the proximal portion of the ileum were collected, fixed and then embedded in paraffin. The tissues were sectioned to roughly $5 \mathrm{~mm}$ small pieces and stained (hematoxylin and eosin). Ten well-oriented villi per sample were selected and measured using a simple microscope (Olympus) connected to an image analysis system.

\subsection{Statistical Analysis}

All statistical analyses were performed using the Statistical Analysis System [15]. Means were compared by the method described by Steel and Torrie [16] and a significant level was obtained by the Duncan multiple-range test [17].

\subsection{Ethical Approval}

The study was approved by the Committee on Care and Use of Animals, King Saud University, Saudi Arabia (1127/18/DAP). 


\section{Results}

\subsection{Growth Performance}

The results of growth performance for the control and experimental groups are provided in Table 2. Feed intake was significantly $(p<0.01)$ higher in T2 compared to T1. Similarly, BW was significantly $(p<0.01)$ higher in T2 compared to T1 and the positive control. As a result, FCR was significantly $(p<0.01)$ lower in T2 and T3 compared to the positive control. Similarly, PEF was also significantly $(p<0.01)$ higher in T2 and T3 compared to the positive control. Although PEF in T1 was not significantly different from T2 and T3, values were slightly better in T2 and T3 compared to T1.

Table 2. Means $\pm \mathrm{SE}$ of feed intake (FI), body weight (BW), feed conversion ratio (FCR), body weight $(\mathrm{BW})$ and performance efficiency factor (PEF) for the cumulative starter period (0 to 15 days of age).

\begin{tabular}{ccccc}
\hline Treatment & FI (g) & BW (g) & FCR (g:g) & PFE \\
\hline Negative control & $437.0^{\mathrm{a}, \mathrm{b}}$ & $346.9^{\mathrm{a}}$ & $1.259^{\mathrm{d}}$ & $196.6^{\mathrm{a}}$ \\
Positive control & $426.8^{\mathrm{a}}$ & $282.9^{\mathrm{c}}$ & $1.511^{\mathrm{a}}$ & $134.6^{\mathrm{d}}$ \\
T1 & $391.4^{\mathrm{b}}$ & $281.9^{\mathrm{c}}$ & $1.390^{\mathrm{b}}$ & $150.5^{\mathrm{b}, \mathrm{c}, \mathrm{d}}$ \\
T2 & $440.8^{\mathrm{a}}$ & $321.5^{\mathrm{a}, \mathrm{b}}$ & $1.374^{\mathrm{b}, \mathrm{c}}$ & $171.3^{\mathrm{b}}$ \\
T3 & $416.3^{\mathrm{a}, \mathrm{b}}$ & $314.0^{\mathrm{b}}$ & $1.329^{\mathrm{c}}$ & $165.8^{\mathrm{b}, \mathrm{c}}$ \\
SEM \pm & $11.46^{\mathrm{b}}$ & $9.12^{\mathrm{n}}$ & 0.019 & 8.19 \\
$p$ value & 0.0005 & 0.0001 & 0.0001 & 0.0001
\end{tabular}

\footnotetext{
$\mathrm{a}, \mathrm{b}, \mathrm{c}$ Means within a column differ significantly $(p<0.01)$. T1, infected + avilamycin at a rate of $0.2 \mathrm{~g} / \mathrm{kg}$; T2, infected + probiotics that have viable spores $\left(2 \times 10^{7} \mathrm{CFU} / \mathrm{g}\right)$ of Bacillus subtilis (ATCC PTA-6737); T3: infected + B. subtilis (DSM 17299;1.2 × 106 CFU/g).
}

\subsection{Intestinal Histology}

The effects of $B$. subtilis on histological structures of broiler chickens are presented in Table 3. Villus height was significantly $(p<0.01)$ higher in T2 compared to all other treatments. However, villus width and surface area were significantly $(p<0.01)$ higher in T1 compared to the positive control group. Villus width was not statistically significant between the negative control and T1 groups.

Table 3. Means \pm SE of villi height $(\mathrm{L})$, width $(\mathrm{W})$ and villi total area (TA) of ileum in broiler chickens at 15 days.

\begin{tabular}{cccc}
\hline Treatment & Villus Height $(\boldsymbol{\mu m})$ & Villus Width $(\boldsymbol{\mu m})$ & Total Area $\left(\mathbf{m m}^{\mathbf{2}}\right)$ \\
\hline Negative control & $4^{\mathrm{c}}$ & $76.7^{\mathrm{a}}$ & $0.100^{\mathrm{b}, \mathrm{c}}$ \\
Positive control & $4^{\mathrm{c}}$ & $64.17^{\mathrm{b}}$ & $0.085^{\mathrm{d}}$ \\
T1 & $544^{\mathrm{b}}$ & $73.9^{\mathrm{a}}$ & $0.124^{\mathrm{a}}$ \\
T2 & $614^{\mathrm{a}}$ & $57.6^{\mathrm{b}, \mathrm{c}}$ & $0.110^{\mathrm{b}}$ \\
T3 & $562^{\mathrm{b}}$ & $61.1^{\mathrm{b}, \mathrm{c}}$ & $0.108^{\mathrm{b}, \mathrm{c}}$ \\
SEM \pm & 11.96 & 2.79 & 0.004 \\
$p^{\text {value }}$ & 0.0001 & 0.0001 & 0.0001 \\
\hline
\end{tabular}

a,b,c Means within a column differ significantly $(p<0.01)$. T1, infected + avilamycin at the rate of $0.2 \mathrm{~g} / \mathrm{kg}$; T2, infected + probiotics that have viable spores $(2 \times 107$ CFU/g) of B. subtilis (ATCC PTA-6737); T3: T3, infected $+B$. subtilis (DSM $172991.2 \times 10^{6} \mathrm{CFU} / \mathrm{g}$ ).

\section{Discussion}

In the current study, growth performance and intestinal histological parameters were improved in the probiotic-treated birds infected with Salmonella. The results were similar to those of the antibiotic-treated birds. Probiotics are considered one of the viable alternatives to antibiotics, particularly in view of the recent ban of regular use of AGPs in poultry diet [6]. In the present study, the growth performance and intestinal architecture were significantly deteriorated in the Salmonella-infected birds. Reduced growth and lesion in the intestinal villi are some of the most prominent signs of salmonellosis, leading to heavy economic losses [8]. 
Interestingly, the results of the probiotic-treated birds were comparable to those of the birds fed antibiotic supplements. The improved growth performance of broilers infected with different kinds of pathogens such as Clostridium and Salmonella in response to supplementation of B. subtilis or phytogentics has been published recently $[8,9]$. The positive effects of probiotics are well documented, e.g., improved performance (body weight gain and feed conversion rate); enhanced immune response and healthy intestine [11]. The effects of the two types of probiotics on the performance of the birds were not significantly different. The efficacy of probiotic use is linked to genetics, nutritional status, frequency, dose, specificity of the strain, survival and stability [11]. A number of mechanisms through which probiotics produce positive effects are involved, such as the reduction of intestinal $\mathrm{pH}$, production of volatile fatty acids and suppression of pathogenetic bacteria through competitive exclusion [18].

As indicated in the current study, villus dimensions were restored as an effect of probiotic supplementation. Dietary probiotics have been shown to enhance the intestinal microbiome in a positive direction [8,9]. The intestinal villi secrete different kinds of defensive mucins such as MUC2 and MUC3 from the goblet cells [11]. In addition, probiotic bacteria improve the humoral and cellular immunity through increased production of delayed hypersensitivity, respiratory burst of macrophages, antibody production, natural killer cells, interleukins, cytokines, antibody-secreting cells and T lymphocytes [11,18].

\section{Conclusions}

Dietary supplementation with B. subtilis improved the growth performance and gut health of Salmonella-infected broiler chickens.

Author Contributions: Formal analysis, M.H.A.; Investigation, A.A.S.; Methodology, M.A.N.; Project administration, A.M.A.

Funding: This research was funded by the Deanship of Scientific Research at King Saud University, grant number RGP-273.

Conflicts of Interest: The authors have no conflict of interest.

\section{References}

1. Khan, R.U.; Naz, S.; Javadani, M.; Nikousefat, Z.; Selvaggi, M.; Tufarelli, V.; Laudadio, V. The use of turmeric (Curcuma longa) in poultry diets. Worlds Poult. Sci. J. 2012, 68, 97-103. [CrossRef]

2. Chand, N.; Faheem, H.; Khan, R.U.; Qureshi, M.S.; Alhidary, I.A.; Abudabos, A.M. Anticoccidial effect of mananoligosacharide against experimentally induced coccidiosis in broiler. Environ. Sci. Poll. Res. 2016, 23, 14414-14421. [CrossRef] [PubMed]

3. Khan, R.U.; Naz, S.; Nikousefat, Z.; Tufarelli, V.; Javdani, M.; Qureshi, M.S.; Laudadio, V. Potential applications of ginger (Zingiber officinale) in poultry diet. Worlds Poult. Sci. J. 2012, 68, 245-252. [CrossRef]

4. Khan, R.U.; Naz, S.; Nikousefat, Z.; Tufarelli, V.; Laudadio, V. Thymus vlugaris alternative to antibiotics in poultry feed. Worlds Poult. Sci. J. 2012, 68, 401-408. [CrossRef]

5. Alzawqari, M.H.; Al-Baddany, A.A.; Al-Baadani, H.H.; Alhidary, I.A.; Khan, R.U.; Aqil, G.M.; Abdurab, A. Effect of feeding dried sweet orange (Citrus sinensis) peel and lemon grass (Cymbopogon citratus) leaves on growth performance, carcass traits, serum metabolites and antioxidant status in broiler during the finisher phase. Environ. Sci. Poll. Res. 2016, 23, 17077-17082. [CrossRef]

6. Abudabos, A.M.; Alyemni, A.H.; Dafallah, Y.M.; Khan, R.U. The effect of phytogenic feed additives to substitute in-feed antibiotics on growth traits and blood biochemical parameters in broiler chicks challenged with Salmonella typhimurium. Environ. Sci. Poll. Res. 2016, 23, 24151-24157. [CrossRef] [PubMed]

7. Dhama, K.; Latheef, S.K.; Mani, S.; Samad, A.H.; Karthik, K.; Tiwari, R.; Khan, R.U.; Alagawany, M.; Farag, M.R.; Alam, G.M.; Laudadio, V.; Tufarelli, V. Multiple beneficial applications and modes of action of herbs in poultry health and production-A review. Int. J. Pharmacol. 2015, 11, 152-176. [CrossRef]

8. Abudabos, A.M.; Alyemni, A.H.; Dafalla, Y.M.; Khan, R.U. Effect of organic acid blend and Bacillus subtilis alone or in combination on growth traits, blood biochemical and antioxidant status in broilers exposed to Salmonella typhimurium challenge during the starter phase. J. Appl. Anim. Res. 2017, 45, 538-542. [CrossRef] 
9. Abudabos, A.M.; Alyemni, A.H.; Dafalla, Y.M.; Khan, R.U. The effect of phytogenics on growth traits, blood biochemical and intestinal histology in broiler chickens exposed to Clostridium perfringens challenge. J. Appl. Anim. Res. 2018, 46, 691-695. [CrossRef]

10. Wilson, K.M.; Bourassa, D.V.; Davis, A.J.; Freeman, M.E.; Buhr, R.J. The addition of charcoals to broiler diets did not alter the recovery of Salmonella typhimurium during growth. Poult. Sci. 2016, 95, 694-704. [CrossRef] [PubMed]

11. Khan, R.U.; Naz, S. Application of probiotics in poultry production. Worlds Poult. Sci. J. 2013, 69, 621-632. [CrossRef]

12. Alhidary, I.A.; Abdelrahman, M.M.; Khan, R.U. Comparative effects of direct-fed microbial alone or with a traces mineral supplement on the productive performance, blood metabolites and antioxidant status of grazing Awassi lambs. Environ. Sci. Poll. Res. 2016, 23, 25218-25223. [CrossRef] [PubMed]

13. Shah, M.; Zaneb, H.; Masood, S.; Khan, R.U.; Ashraf, S.; Sikandar, A.; Faseeh, H.; Rehman, U.R.; Rehman, H. Effect of dietary supplementation of zinc and multi-microbe probiotic on growth traits and alteration of intestinal architecture in broiler. Probiotics Antimicrob. Proteins 2018. [CrossRef] [PubMed]

14. Rahman, S.; Khan, S.; Chand, N.; Sadique, U.; Khan, R.U. In vivo effects of Allium cepa L. on the selected gut microflora and intestinal histomorphology in broiler. Acta Histochem. 2017, 119, 446-450. [CrossRef] [PubMed]

15. SAS. Statistical Analysis System User's Guide; Statistics Version 9.1; SAS Institute: Cary, NC, USA, 2003.

16. Steel, R.G.D.; Torrie, J.H.; Dieky, D.A. Principles and Procedures of Statistics, 3rd ed.; McGraw Hill Book Co., Inc.: New York, NY, USA, 1997.

17. Duncan, D.B. Multiple range and multiple F-test. Biometrics 1955, 11, 1-42. [CrossRef]

18. Khan, R.U.; Naz, S.; Dhama, K.; Karthik, K.; Tiwari, R.; Abdelrahman, M.M.; Alhidary, I.A.; Zahoor, A. Directfed microbial, Beneficial applications, modes of action and prospects as a safe tool for enhancing ruminant production and safeguarding health. Int. J. Pharmacol. 2016, 12, 220-231.

(C) 2019 by the authors. Licensee MDPI, Basel, Switzerland. This article is an open access article distributed under the terms and conditions of the Creative Commons Attribution (CC BY) license (http://creativecommons.org/licenses/by/4.0/). 